Michelle R. Garfinkel and

Daniel L. Thornton

Michelle A. Garfinkel, an assistant professor at the University of California at Inine, was a senior economist at the Federal Reserve Bank of St. Louis while this paper was written. Daniel $L$. Thornton is an assistant vice president at the Federal Reserve Bank of St. Louis. Richard i. Jako provided research assistance.

\title{
Alternative Measures of the Monetary Base: What Are the Differences and Are They Im-
} portant?

$\mathbf{T}$ eserve requirements, is a measure intended to summarize the net effect of all Federal Reserve actions on the money stock. ${ }^{1}$ As such, it serves as an indicator of the effects of monetary policy actions on the money stock.

Because of the Federal Reserve Bank of St. Louis' long-standing interest in monetary policy, it began publishing a series on the adjusted monetary base in August 1968..$^{3}$ Nearly 11 years later, the Federal Reserve Board began publishing an alternative series. While the objective of the Board's series is the same, it has always differed from the series constructed by the St. Louis Fed in a number of respects. These differences have changed over time with changes in the structure of reserve requirements and, thus, changes in the methods of calculating the re. spective series. ${ }^{3}$

The two series have been used separately and, on occasion, jointly to address a number of issues of importance in monetary theory and policy. Occasionally, they have yielded significantly different results. ${ }^{4}$ Moreover, at times

\footnotetext{
The idea of adjusting the monetary base to reftect changes in reserve requirements was proposed initially by Karl Brunner (1961) in an effort to formulate an "empirically significant theory" of the money supply process. Brunner called this adiustment "liberated reserves." He was the first to compile data on the adjusted monetary base and empifically investigate the relationship between his measure and the money supply. This research agenda was pursued by both him and Allan Meltzer in a number of articles dealing with the money supply process and monetary policy.

2See Andersen and Jordan (1968).
}

3One of the most dramatic changes in the structure of reserve requirements occurred with the implementation of the Monetary Control Act of 1980 (MCA). Garfinkel and Thornton (1989) discuss the changes in the structure of reserve requirements brought about by the phase-in of the MCA. Garfinkel and Thornton (1991) discuss the effects of the MCA on the money supply process and the usefulness of the monetary base as an indicator of the effect of monetary policy on the money stock. See Burger and Rasche (1977) and Gilbert (1987) for two significant changes in the calculation of the St. Louis adjusted monetary base.

4 See Friedman (1988), McCallum (1988a,b). Haslag and Hein (1990) and Muelendyke (1990) for some examples of differential performance. 


\section{Figure 1}

\section{Levels of the STL-AMB and BOG-AMB, Seasonally Adjusted}

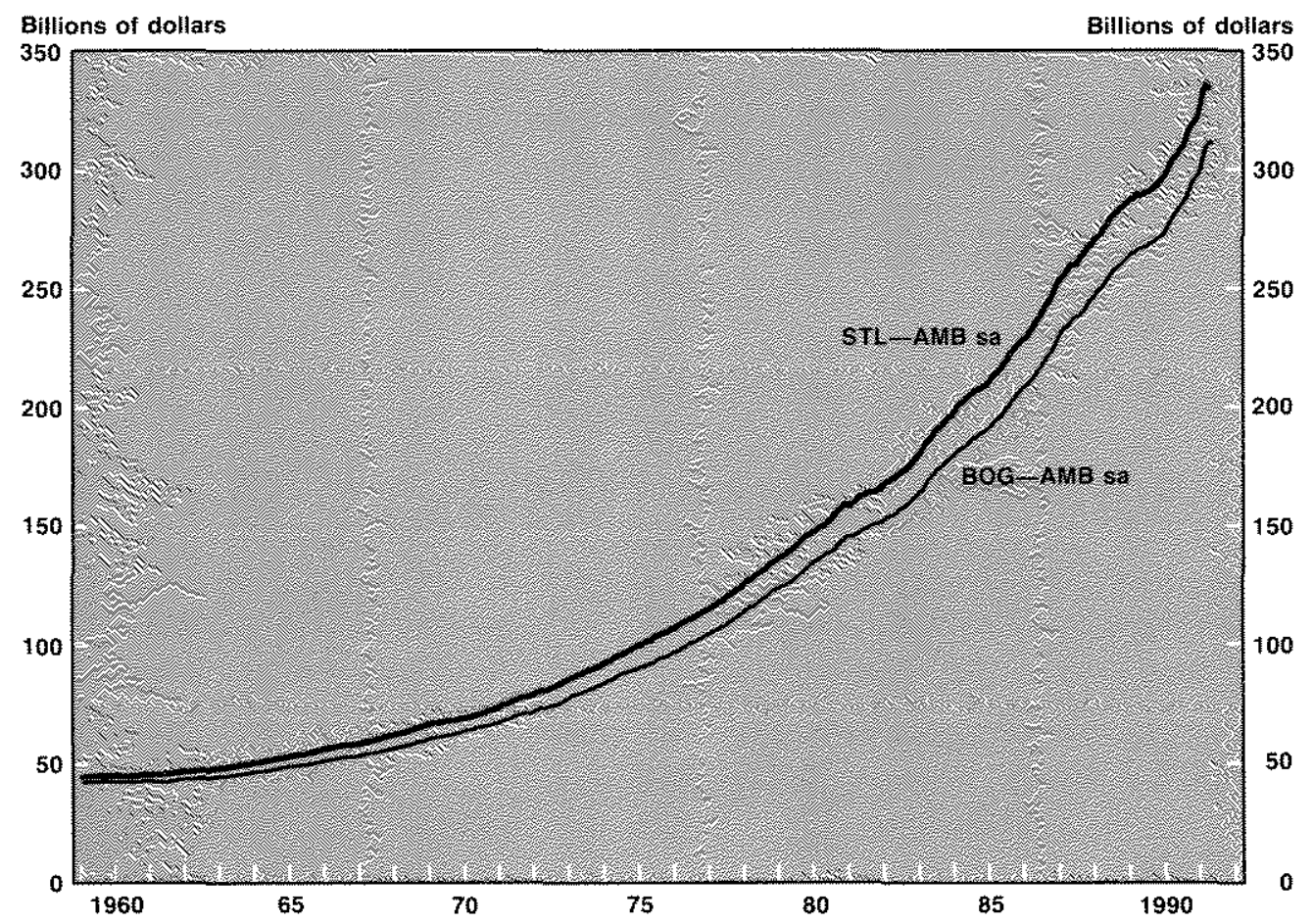

Data plotted from Janvary 1959 thru April 1991.

they have presented conflicting pictures of monetary policy.

Because of changes in their calculation and the recent conflicting results, now seems to be an appropriate time to re-examine these series to see how and why they differ, both historically and currently. We can also investigate whether they are likely to continue to behave differently in the years ahead and whether their differential performance is attributable to fundamental differences or merely to arbitrary differences in their construction. Finally, we will provide preliminary evidence on whether the existing difference is potentially important for money stock control.

\section{THE DIFFERENCE BETWEEN THE TWO ADUUSTED MONETARY BASE MEASURES}

The adjusted monetary base series constructed by the St. Louis Fed (hereafter labeled STL-
AMB) and that constructed by the Board of Governors of the Federal Reserve System thereafter labeled BOG-AMB) were designed for the same purpose. Each is intended to isolate the effects of monetary policy actions-that is, changes in the supply of reserves and changes in reserve requirements - in a single measure. Nevertheless, the two series are quite different.

\section{How Do They Differ?}

The difference in their behavior can be seen in figure 1 , which shows both adjusted monetary base measures, seasonally adjusted, from January 1959 to April 1991. Although the two measures behave similarly throughout the sam. ple period, STL-AMB is always larger than BOG$A M B$ and the spread between them increases over time. As will be discussed later, much of this spread can be attributed to differences in the reserve requirement measure used to calculate the two series. Currently, this difference is 
Figure 2

Difference Between the Growth Rates of STL-AMB and BOG-AMB

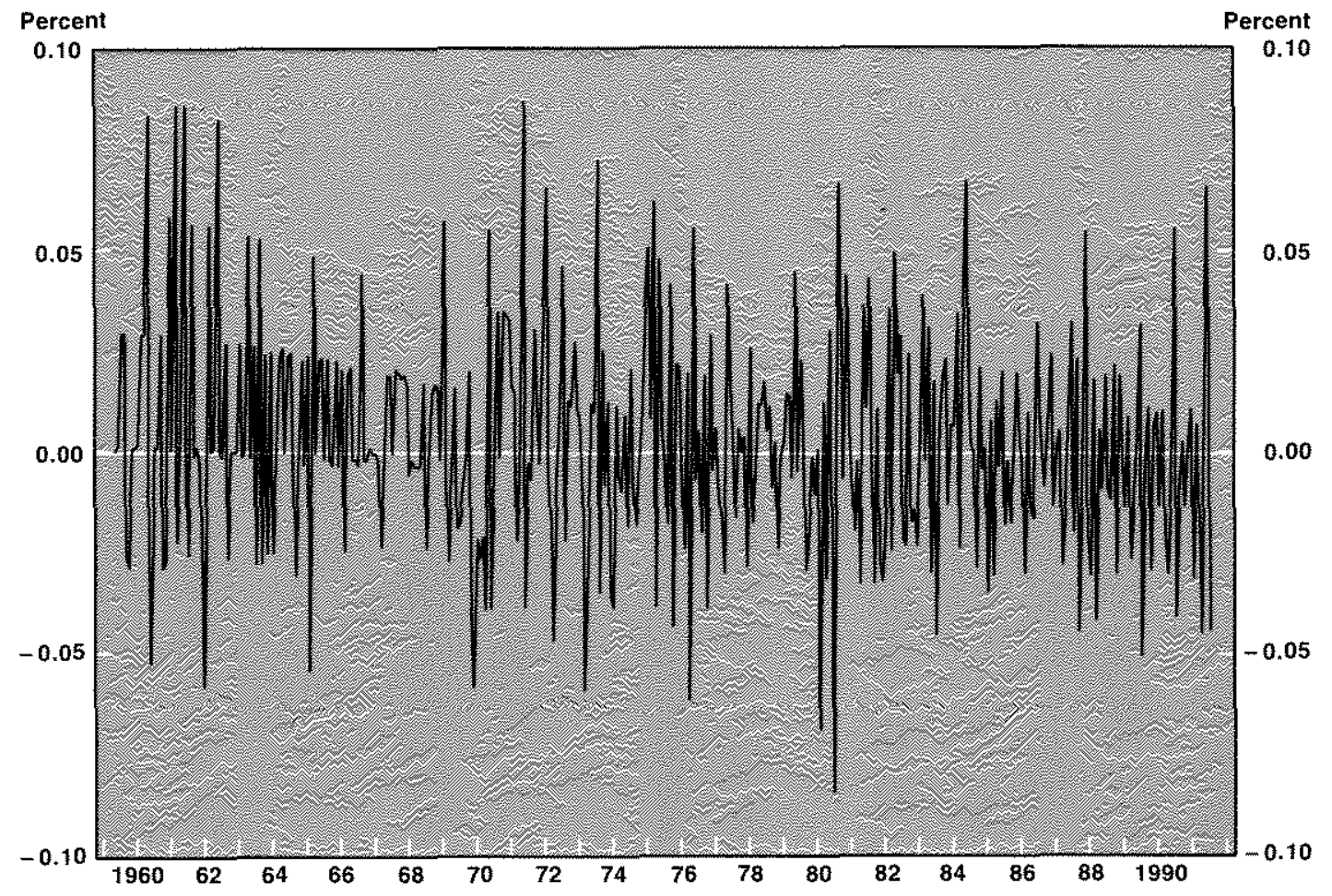

Data plotted from February 1959 thru April 1991.

due to the weight each assigns to the level of transaction deposits. As a consequence, the recent widening in the spread between the two AMB series is driven by the growth of deposits. ${ }^{5}$

Although the difference in the level of the two series gets larger over time, figure 2 shows that the difference in the monthly compounded annual growth rates of the two adjusted monetary base measures does not exhibit a significant trend. Indeed, although the monthly difference in the growth rates ranges from -8.4 percent to 8.6 percent, the average difference in their growth, 0.18 percent, is not significantly different from zero at the 5 percent significance level (the t-statistic is 1.35 ). Thus, over a sufficiently long period, the growth rates of the two series are nearly identical.

Over shorter periods, however, the differences in the growth rates of these aggregates persist, as illustrated by a six-month moving average of the difference between the growth rates of the two series-presented in figure 3. The six-month moving average, which ranges from -3.6 percent to 3.4 percent, shows that,
5Thus, the series should be strongly cointegrated. Haslag and Hein (1990), using data from 1959 through 1989 , find that the two adjusted monetary base measures are coinm tegrated. Their results, based on a procedure suggested by Engle and Granger (1987), indicate that the null hypoth. esis of no cointegration can be rejected at the 5 percent level. This hypothesis, however, cannot be rejected at the percent level. Nevertheless, alternative tests for cointegration, using a procedure developed by Johansen (1988), add futher support to the notion that the two ser- ies are cointegrated This procedure and others are discussed in Dickey, Jansen and Thornton (t991).] The chisquare statistic for the null hypothesis that there is one cointegrating vector is 74.5 , compared with a critical value at the 1 percent significance level of 22 , which provides evidence that the two monetary base series are cointegrated, as expected. 
Figure 3

A Six-Month Moving Average of the Difference Between
the Growth Rates of STL-AMB and BOG-AMB

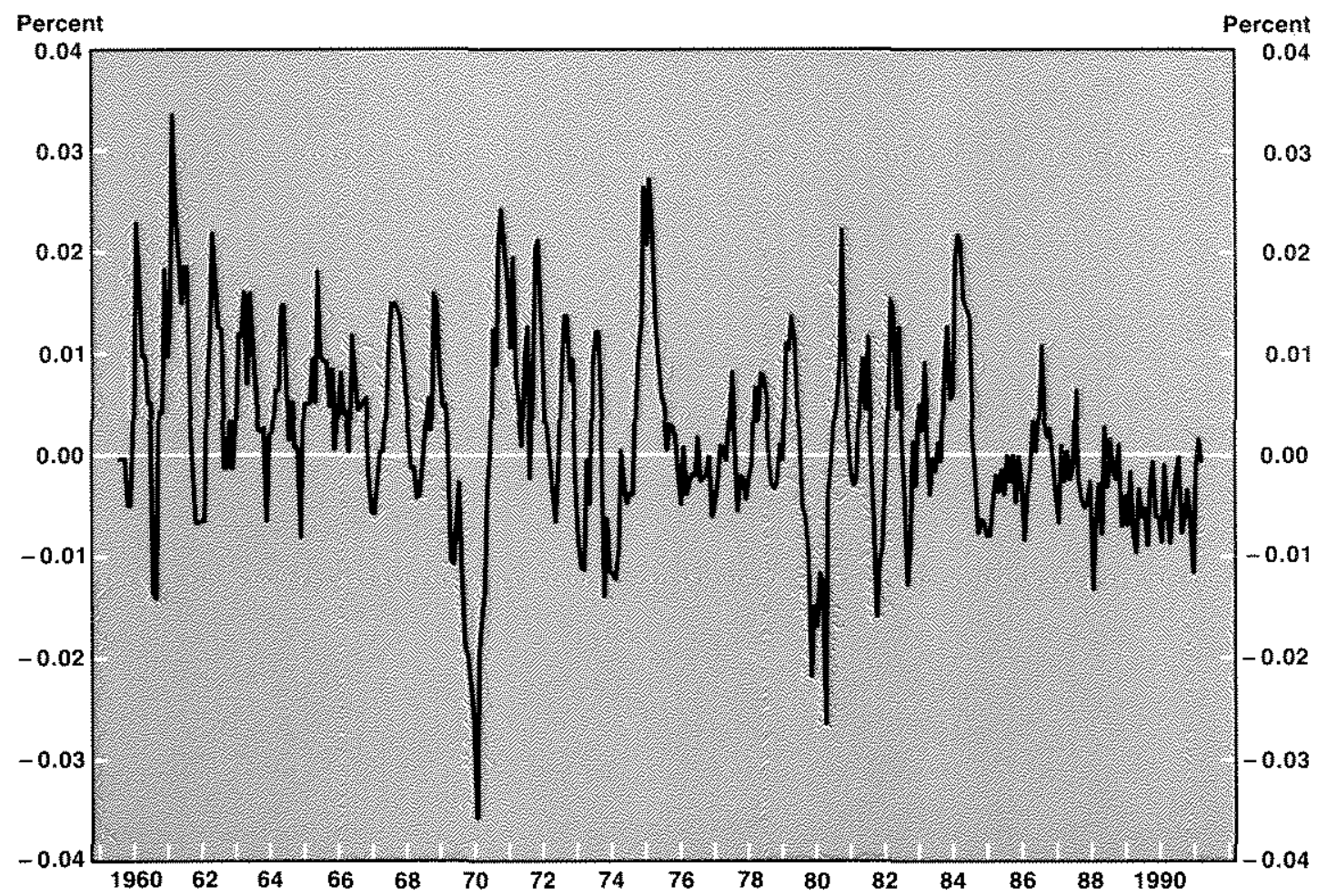

Data plotted from July 1959 thru April 1991.

for periods as long as six months, the two adjusted monetary base measures can give considerably different pictures of monetary policy. In fact, as an examination of figure 3 shows, the growth rates of the two series can differ significantly even for fairly long periods of time. For example, the six-month moving average of the difference in the growth rates was strictly positive before April 1969 and nearly always negative after August 1984. The difference in the monthly growth rates averaged 0.60 percent during the former period and -0.32 percent during the latter, and both differences are statistically significant (the t-statistic is 7.96 in the former period, 7.04 in the latter).

\section{Why Do They Differ?}

Much of the difference in the two series is attributable to the method of adjusting for reserve requirement changes. Each adjustment creates an index of reserves that would have been held during some "base period." The magnitude of this adjustment, hereafter referred to as RAM, reflects the reserves that are absorbed (released) if the reserve requirements were higher (lower) than those in effect during the base period. ${ }^{6}$

When the STL series was first created, a bank's reserve requirements depended on its location, the type of deposits it held (transaction vs. non-transaction) and whether it was a mem-

${ }_{6}^{6}$ Only the STL refers to this adjustment as RAM-short for 
ber of the Federal Reserve System. ${ }^{\gamma}$ The adjust* ment for reserve requirement changes was made by multiplying the deposits in a given reserve category by the difference between that cate. gory's reserve requirement in the base period and its corresponding reserve requirement in the current period. The initial base period used was from August 1935 to July $1936 . .^{*}$

In contrast, the BOG has always used the current period as the base period in calculating its reserve adjustment. Thus, each time reserve requirements change, the $\mathrm{BOG}$ revises the historical data to reflect the "current" system of reserve requirements. For example, when reserve requirements are reduced, the $\mathrm{BOG}$ calcu. lates the amount of reserves that would have been required had the lower reserve require. ment been in effect previously. The actual level of required reserves in past periods are multiplied by the ratio of the new average reserve requirement to the old, thereby creating a new, counterfactual "adjusted reserve" series. In this example, the new historical series for adjusted reserves would be lower than the previous historical series. The lower level of the "new" historical series relative to the current period's levels reflects a hypothetical release of reserves in the past brought about by the decrease in requirements in the current period.

In essence, both the STL and BOG methods create counterfactual series for adjusted reserves. For STL, the counterfactual series is the reserves that would have been held if the historical reserve requirements were in effect today. Hence, if reserve requirements have been reduced (raised), actual reserves would be lower (higher) than adjusted reserves. For the BOG, the counterfactual series is the reserves that would have been held in the past if the current reserve requirements were in effect. Actual reserves held in the past would be higher (lower) than adjusted reserves if reserve requirements were reduced (raised) in the current period.

With the STL approach, it is not necessary to revise the historical monetary base series each time reserve requirements are changed. As not ed above, the BOG series, in contrast, requires that all historical data be revised, which means there is a delay in the availability of data. Consequently, the STL approach has a comparative advantage for empirical research over the BOG approach because it produces a series that is readily avalable at the time it is most neededwhen there is a change in reserve requirements. ${ }^{9}$ Beyond this advantage, the base-period distinction between these approaches appears to be unimportant.

\section{A Recent Change in the Construc- tion of the STL Series}

In 1987 the STL adjusted monetary base series was revised in response to fundamental changes in the structure of reserve require. ments associated with the Monetary Control Act (MCA) of 1980. Currently, the series is obtained by splicing two adjusted monetary base series with RAMs based on different systems of reserve requirements. Before November 1980 , RAM is based on average ratio of reserves to deposits, for transaction and non-transaction deposits, during the period from January 1976 to August 1980. After November 1980, RAM is based on the structure of marginal reserve requirements on transaction deposits in effect un der the MCA. These series are spliced together at the first reserve maintenance period Novem-
7Prior to MCA, non-member banks did not have to maintain reserves with the Federat Reserve System. At the time the Federal Reserve Act was passed, reserve requirements were different for "central reserve cily." "reserve city" and "country" banks. This distinction was rot based explicitly on the size of the institution, but on the location of the bank at the time the Federal Reserve Act was passed. Over time, this classification system became less meaningful, with many large banks classified as country banks.

s See Burger and Rasche (1977), Gibert (1980) and Tatom (1980).

${ }^{9}$ Although reserves absorbed or released by onanges in reserve requirements typically are offset through open market operations so that there is no marked change in the adjusted monetary base, RAM does change significantIy. It should be noted, however, that the base pertod for the St. Louis series has changed when fundamental changes in the structure of reserve requirements made it difficult or impossible to continue using the original base period. At these times, the historical data were revised. The first of these changes occurred in 1977 when Burger and Rasche (1977) aitered the series by both changing the method used to calculate AAM and adjusting the series to account for the significant change in the structure of reserve requirements in November 1972 . The next occurred in December 1980 when the base period was changed to the period from January 1976 to August 1980 The most recent, discussed next, was in 1987 . 
ber 19,1980 ) under the new reserve requirements imposed by the MCA. ${ }^{10}$

At the splice date, the second part of the series is calculated under the assumption that the marginal reserve requirements on reservable categories of time and savings deposits are zero. ${ }^{11}$ Reserve requirements on all non-transaction deposits were eliminated in December 1990. Consequently, after November 1980, the STL series utilizes the present structure of reserve requirements for its base period. Because the base period for the BOG's series is always the current one, the "base-period" distinction between the two series has been virtually eliminated for the period since November $1980,{ }^{12}$ This distinction remains relevant for the preNovember 1980 data, however.

Another distinction remains, however. STL calculates its RAM using the marginal reserve requirement on transaction deposits, 12 percent, while the BOG uses the average reserve requirement ratio at the time of the last change in reserve requirements. Currently, this ratio is about 8 percent for transaction deposits. ${ }^{13}$ As a result, the level of STL-AMB is larger than that of BOG-AMB.

\section{DETERMINING THE SOURCE OF THE DIFFERENCES BE'TWEEN THE TWO SERIES}

Although the difference in adjustment methods for reserve requirement changes accounts for much of the difference exhibited by the two monetary base series, it is not the entire source of their differential behavior. There are two other potentially significant sources: the treat- ment of vault cash and the seasonal adjustment methods used. Each of these three sources and their empirical importance is discussed below. (A more detailed discussion of the current construction of the two series and their differences appears in the appendix.)

\section{The Treatment of Vault Cash}

Currently, the two adjusted monetary base series start with slightly different "raw" data. Both unadjusted monetary base measures, roughly speaking, are the sum of reserve balances held by depository institutions at Federal Reserve Banks and currency in circulation-in other words, currency held by the public, including depository institutions. The differences in these raw data lies primarily in the treatment of vault cash-that is, cash held by depository institutions in their vaults. The BOG, in contrast to STL, adjusts its series for the timing of reserve requirements as satisfied by depository institutions with vault cash.

To get a better understanding of this difference, it is helpful to review briefly the Federal Reserve's system of reserve requirements. Under the current system, depository institutions are required to hold reserves in the form of vault cash and/or reserve balances at the Federal Reserve equal to a fixed percentage of their reservable deposit liabilities-specifically, transaction deposits held by the public, government and foreigners. ${ }^{14} \mathrm{~A}$ depository institution's required reserves are calculated on the basis of the transaction deposits it holds during a twoweek period ending every other Monday. An institution can satisfy its requirements with deposit balances at the Federal Reserve during the two-week reserve-maintenance period ending
10The procedure scales the "older" part of the series down to the level of the "newer" part of the series to reach the level consistent with the post-MCA base period. The growth rates of the data before the splice date are unaffected by the change in the base-period for the level data. See Gilbert (1987), p. 26, for a detalled discussion of the procedure.

1This was done because the data necessary for making a RAM adjustment for non-transaction deposits were not available. See Gilbert (1987).

T2The only base-period distinction that remains is due to the fact that the Garn-St. Germain Depository Institutions Act of 1982 requires that a certain level of transaction deposits at each depository institution be subject to a reserve requirement of zero and that this rate be adjusted upward with the rise in total reservable liabilities.

13Because the average ratio of reserves held against transaction deposits to transaction deposits for the period from
January 1976 to August 1980 was 0.12664 , the use of the marginal reserve requirement, rather than the average ratho of reserves to deposits previously used, minimizes the difference between the "older" and "newer" series at the splice date.

34There are lower reserve requirements on a tranche of deposits for each depository institution. Also, depository institutions are required to maintain reserves against their net checkable deposits with other institutions. Aggregated over all institutions, however, the net deposits are zero. Consequently, in the aggregate, no reserves are held against checkable deposits with other depository institutions. Because reserve balances held against such deposits do not net out to zero for individual institutions, however, reserves held against net "inter-bank" checkable deposit liabilities affects the distribution of required reserves among these institutions. 
two days after the period used in computing its reserves, and with vault cash held during a two-week period ending 30 days before the end of the maintenance period. Vault cash used to satisfy statutory reserve requirements is called "applied vault cash."

The BOG's adjustment for vault cash involves a distinction between "bound" institutions, whose statutory reserve requirements exceed their holdings of vault cash, and "non-bound" institutions, whose vault cash exceeds their statutory reserve requirements. Another important distinction is between weekly reporting institutions, called EDDS, and quarterly reporting institutions, called QEDS. In the BOG's adjustment for vault cash, the difference between current vault cash and lagged (applied) vault cash of bound EDDS (see appendix) is excluded from the BOG's raw monetary base series. Hence, the STL and BOG unadjusted, not-seasonally-adjusted series effectively differ by the change in vault cash of bound EDDS. ${ }^{15}$

What is the empirical importance of this difference? Because of limited data availability, an exact measure of the magnitude of the BOG's adjustment to vault cash cannot be obtained over the entire sample. As a proxy, the difference between the STL source base and the BOG's notbreak-adjusted monetary base (with no seasonal adjustments) is used. ${ }^{16}$ This measure, denoted here by $\triangle T V C$, is depicted in figure 4 for the full sample period from February 1959 to April 1991. As the figure shows, the difference in the treatment of vault cash fluctuates between $-\$ 2.3$ billion to $\$ 1.7$ billion, but is positive for most of the sample period. Indeed, $\triangle T V C$ averages $\$ .15$ billion over the period. While this average is small, both in absolute terms and relative to the difference in the two base measures, it is statistically significant from zero at the 5 percent level (the t-statistic is 7.82).

As discussed in more detail below, the difference in the treatment of vault cash has a pro-

15They also differ because of "as-of" adjustments, which the BOG makes but STL does not, and because the BOG includes "required clearing balances" in its not-breakadjusted series.

The rationale for the BOG's adjustment to vault cash is not entirely clear. A recent Board memo states that the ad. justment is made on the belief that current valit cash constrains the lending activities of non-bound institutions, while lagged vault cash is the relevant constraint for bound instilutions.

${ }^{16}$ As noted in the appendix, required clearing balances and "as-of" adjustments are included in the Board's not-break- nounced seasonal pattern, which has become more amplified over time. Thus, although the difference in the treatment of vault cash contributes relatively little to the "low-frequency" (quarterly or annual) variation in the difference between the two series, it contributes somewhat to the "high-frequency" (monthly) variation.

\section{The Reserve Adjustment}

Before November 1980, there are two basic differences between the adjustments that STL and the BOG use on the raw data for reserve requirement changes. First, as noted previously, STL uses a fixed, historical period, while the BOG uses the current period as the base period. Because the average ratio of required reserves to deposits was substantially higher during this period than it is today, the STL adjustment before November 1980 is significantly larger than the BOG's. Second, the BOG makes an additional adjustment for changes in reserve requirements on applied vault cash (see appendix for details).

These two differences continue to be relevant after November 1980. Because STL uses the marginal reserve requirement of 12 percent, which is larger than the average ratio of reserves to deposits used by the BOG to calculate its RAM, the levels of the series are quite different even after this date. As in the period before November 1980, the BOG makes, as part of its break-adjustment procedure, a separate adjustment to applied vault cash. In addition, since February 1984, with the switch to contempora* neous reserve accounting, the BOG makes a separate break adjustment to its adjustment for lagged vault cash of bound EDDS.

The difference between the STL adjusted monetary base and the BOG's break-adjusted monetary base can be used to measure the empirical magnitude of differences in the method of adjusting for reserve requirement changes. $\triangle T V C$ is added to this measure to isolate the ef- adjusted monetary base series, but not in the source base. (See table Al of the appendix for detals). Required clearing balances and these "as-of" adjustments, however, are not included in the Board's break-adjusted series and, thus, play no role in explaining the difference between the two adjusted monetary base measures. To isolate the effect of the difference in the treatment of vault cash on the difference between the two series, required clearing balances and the as-of adjustments (when these data are available) are removed from the difference between the two unadjusted base series. 
Figure 4

Difference in the Treatment of Vault Cash $\triangle T V C$

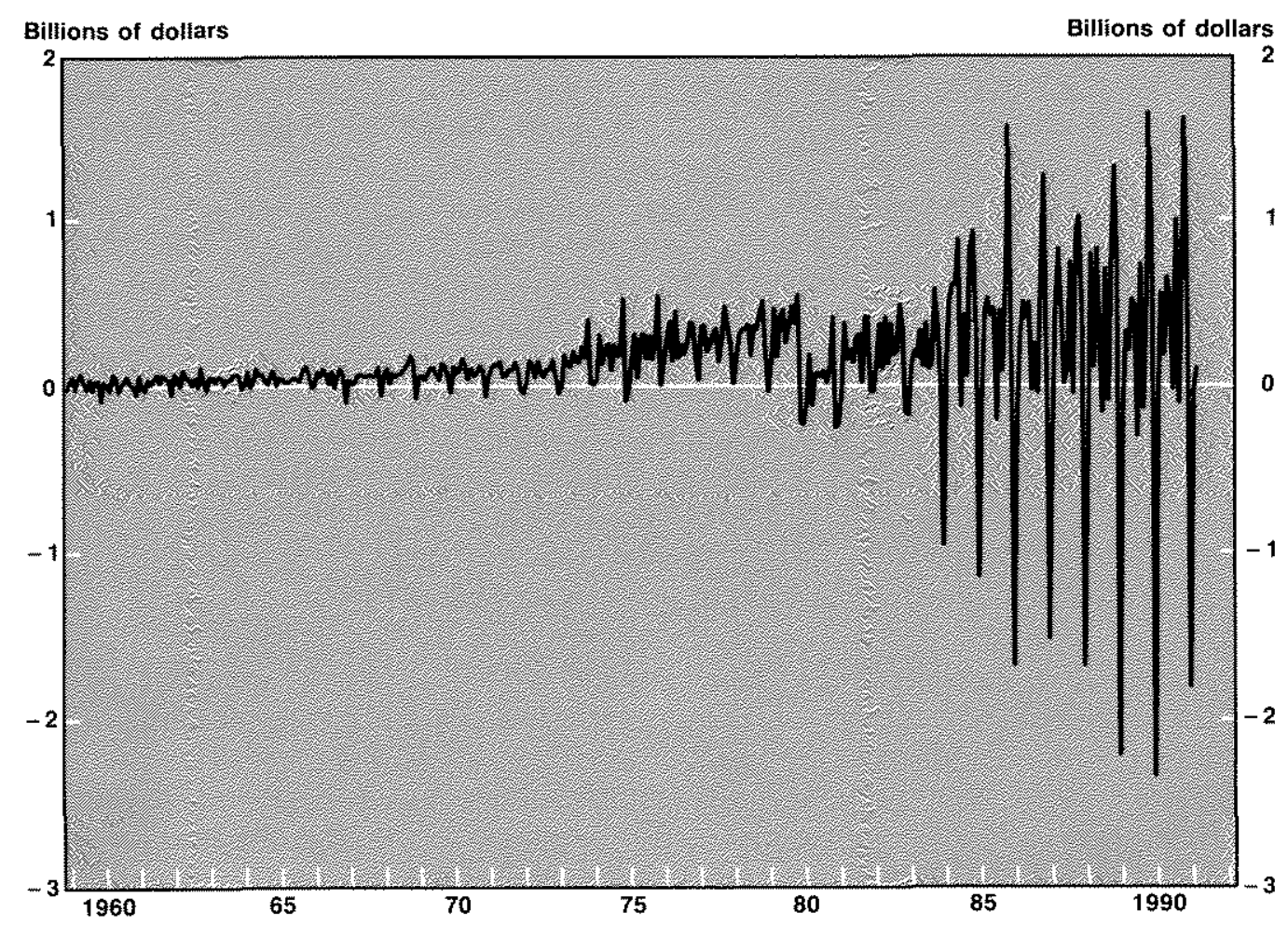

Data plotted from January 1959 thru April 1991.

fect of the difference in RAM from that of the BOG's different treatment of vault cash. The resulting series, denoted here by $\triangle \mathrm{RAM}$, and the difference between the two seasonally adjusted, adjusted monetary base measures, denoted by $\triangle A M B S A$, are presented in figure 5. The figure shows that most of the difference between the levels of the two seasonally adjusted bases is, in fact, explained by differences in the method used to adjust for reserve requirement changes.

\section{Seasonal Adjustment}

To remove regular variations in the AMB series due to seasonal factors, both series are sea- sonally adjusted. For monthly and quarterly data, STL adjusts its monetary base series by simply applying the standard X-11 seasonal adjustment program to its not-seasonally-adjusted series. Weekly data are seasonally adjusted with a separate program that inputs unadjusted weekly data and seasonally adjusted monthly data. ${ }^{x z}$

The BOG seasonally adjusts weekly data using a model-based approach; it then obtains seasonally adjusted monthly and quarterly data from the seasonally adjusted weekly data. ${ }^{18}$ In contrast to STL, the components of the base are seasonally adjusted separately: break-adjusted required reserves against transaction deposits, the break-adjusted measure of surplus vault

\footnotetext{
17 See Zeller (1972). Also, see Gibert (1985) for a discussion of the change in seasonat adjustment assoctated with the switch to contemporaneous reserve accourting.
}

\section{5ee Plerce, Grupe and Cleveland (1984) and Farley and O'Bien (1987) for a discussion of the seasonal adjustment} procedures used by the Board. 


\section{Figure 5 \\ Difference Between STL-AMB and BOG-AMB and the Difference Between Their Reserve Adjustments, $\triangle A M B S A$ and $\triangle R A M$}

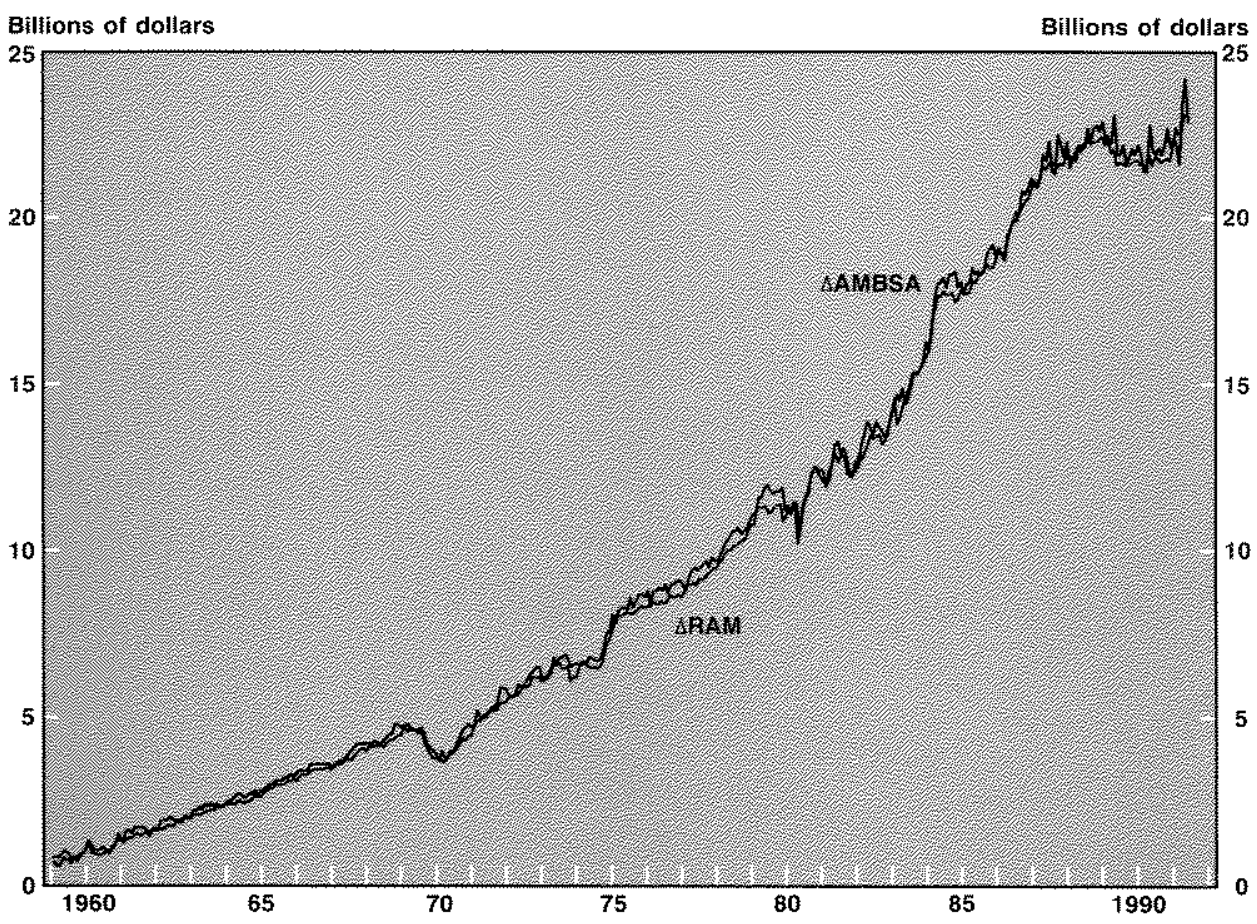

Data plotted from January 1959 thra April 1991.

cash used by the BOG, and currency held by the nonbank public. ${ }^{19}$

The difference in the two series due to different seasonal adjustment procedures is presented in figure 6. This difference, denoted by $\triangle S A M$, is measured by subtracting the BOG's seasonal adjustment (the difference between the seasonally adjusted and the not-seasonally-adjusted, breakadjusted monetary base) from STL's seasonal adjustment (the difference between the seasonally adjusted and the not-seasonally-adjusted, adjusted monetary basel. Not surprisingly, the average difference in the series due to differences in seasonal adjustment is essentially zero over the sample period. ${ }^{20}$ Nevertheless, $\triangle \mathrm{SAM}$ ranges from $-\$ 1.6$ billion to $\$ 2.6$ billion, suggesting that differences in the seasonal adjustment are a source of high-frequency variation in the difference between the two series.

\section{The Relative Importance of These Differences Over Time}

As indicated by figures 4 and 6 , the contribution of the differences in the treatment of vault cash and the seasonal adjustment have become more variable starting shortly after the MCA, especially around 1984. Moreover, after 1984, both differences have large seasonal components. $\triangle T V C$ becomes larger and more variable, perhaps because the BOG's adjustment for lagged

\footnotetext{
${ }^{19}$ All components of the monetary base, excluding excess reserves, are adjusted as a whole before the switch to contemporaneous reserve accounting. For the series after the switch, the weekly sertes is adjusted by component using a model-based procedure and then is modified to be made consistent with the monthy series.
}
${ }^{20}$ The average difference is $\$ .025$ billion, with a i-statistic of 1.14 for the test of the null hypothesis that the difference is zero.




\section{Figure 6 \\ Difference in the Seasonal Adjustment $\Delta$ SAM}

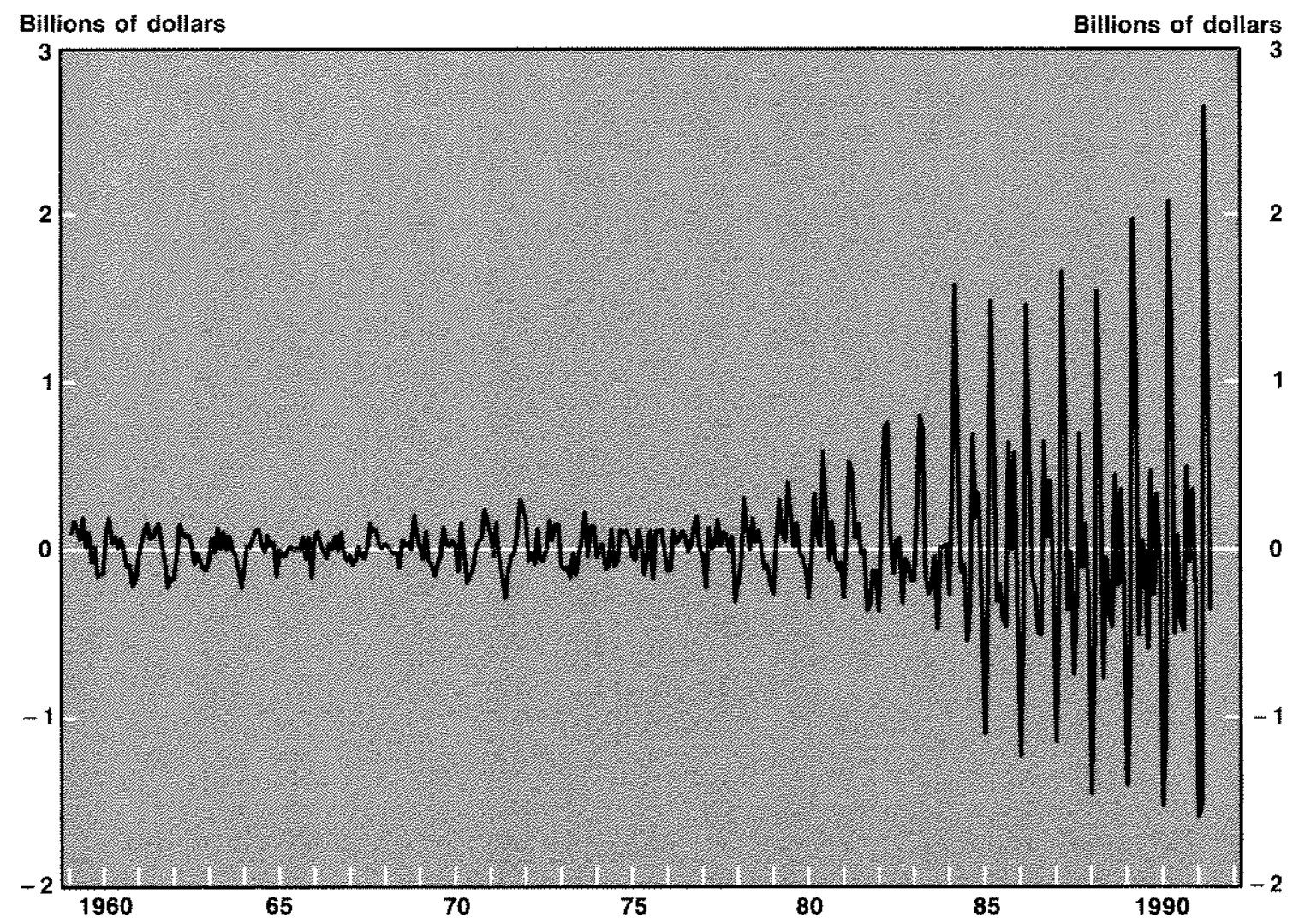

Data plotted from January 1959 thru April 1991.

vault cash at bound EDDS does not change with the Fed's move from lagged to contemporaneous reserve accounting. Separate break adjustments are made to this series and to lagged vault cash at QEDS starting in February 1984, however.

The difference due to seasonal adjustments becomes larger with higher frequency variation about this same time. This may be the result of the Board's changing its seasonal adjustment method in February 1984. ${ }^{21}$

The seasonal variations in these two series tend to offset each other so that the difference between STL-AMB and BOG-AMB does not have a large seasonal component. Indeed, $\triangle T V C$ and $\triangle S A M$ are highly negatively correlated after 1984-the simple correlation between changes in the two series after January 1984 is -.84 .

As shown in table 1, which reports the variances of $\triangle A M B S A, \triangle R A M, \triangle T V C, \triangle S A M$ and ( $\triangle T V C+\triangle S A M)$ for various subperiods, the variability in $\triangle A M B S A$ has also increased over the entire sample period. The subperiods correspond to various reserve requirement regimes. The full sample is broken at the time of the implementation of the MCA and the time of its effective completion, which coincides with the switch to contemporaneous reserve accounting. 2t As noted above, the BOG seasonally adjusts its breakadjusted monetary base as a whole for data before the switch to contemporaneous reserve accounting in February 1984. Thereatter, it has used a model-based approach to seasonalize the components of the base separately for weekly data. In addition, as discussed by Gilbert (1985), the seasonal factors used by the St. Louis Fed also changed around that time. 
Table 1

The Variances of Changes in the Difference between STL-AMB and BOG-AMB and Changes in its Sources

\begin{tabular}{|c|c|c|c|c|c|}
\hline Perrod & ANIISSA & trath & rroc & s s 411 & $4 r v e+1 s A$ \\
\hline $195902-199104$ & 096 & 604 & 245 & 2.990 & 104 \\
\hline $1950.02 \cdot 1960-11$ & 033 & roge & 016 & 019 & 625 \\
\hline 1980.121991 .04 & 216 & 858 & 725 & .858 & 269 \\
\hline $1960,12-198401$ & 120 & 072 & 069 & 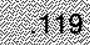 & 094 \\
\hline $198402-190104$ & 256 & 051 & $\left(\mathrm{or}_{1}\right.$ & 181 & 346 \\
\hline
\end{tabular}

\section{Table 2}

\section{Simple Correlations between Changes in the Difference between STL-AMB and BOG-AMB and Changes in its Sources}

\begin{tabular}{|c|c|c|c|c|}
\hline Petrod & $1 \mathrm{nRM}$ & 476 & $\mathrm{AsAM}$ & 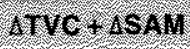 \\
\hline $1959.02,199), 04$ & 2. 206 & 175 & $3 a 4$ & 826 \\
\hline 1659.62 1900 I & 668 & 238 & 488 & 614 \\
\hline $1980.12 .199 / 04$ & 022 & 177 & 360 & 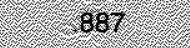 \\
\hline $1980,12-198461$ & 628 & 227 & 4) & 669 \\
\hline $1984.0210970_{4}$ & 156 & 180 & 334 & 825 \\
\hline
\end{tabular}

As the table shows, the variance of changes in the differences of the two seasonally adjusted AMB series has increased throughout the sample period, especially since February 1984, when the variances of both $\triangle T V C$ and $\triangle S A M$ sharply increase. Because these series are negatively correlated, however, this increased variability is not reflected in a similar rise in the variance of these combined series $(\Delta T V C+\Delta S A M)$. Nevertheless, the simple correlations between changes in $\triangle A M B S A$ and both changes in $\triangle R A M$ and changes in $(\triangle T V C+\triangle S A M)$ presented in table 2 show that more of the month-to-month changes in $\triangle A M B S A$ is attributable to changes in $\triangle \mathrm{TVC}+\triangle \mathrm{SAM}$ since January 1984.

\section{ALTERNATIVE MEASURES OF THE MONETARY BASE: ARE THE DIFFERENCES IMPORTANT?}

Since the adjusted monetary base is intended to be a summary measure of the policy actions of the Federal Reserve, an important question arises: are the differences in the STL and BOG measures of the adjusted monetary base important?:2 Over a sufficiently long period of time, the answer to this question is an emphatic, "No!" As noted earlier, over sufficiently long periods of time, the average difference in the growth rates of the two series is negligible. Nevertheless, over shorter
22Garfinkel and Thornton (1991) have shown that the relationship between the money supply ard the adjusted monetary base has weakened since the MCA. More impor- tant, they argue that the usual linear relationship between the money supply and the monetary base, as a model of the money supply process, faits to perform well since then. 
Table 3

Estimate of Changes in M1 on Changes in Alternative Measures
of the Adjusted Monetary Base Monthly Results

\begin{tabular}{|c|c|c|c|c|c|c|c|c|}
\hline \multirow[b]{2}{*}{ Perlod } & \multicolumn{2}{|c|}{ St loous } & \multirow[b]{2}{*}{1} & \multirow[b]{2}{*}{ o.w } & \multicolumn{2}{|r|}{ Bord } & & \\
\hline & Constant & Aamb & & & constent & 4AMB & 6 & 94 \\
\hline 195902,1980010 & $(0.85)$ & $(13.86)$ & 424 & 169 & $(175)$ & $(12.287)$ & 848 & $1 \% 5$ \\
\hline 198011.196402 & $(0.961)$ & $(8,025)$ & 210 & 2.1 & $(0.51)$ & $\left(\begin{array}{l}2594 \\
(8.23)\end{array}\right.$ & 195 & 2.15 \\
\hline 198408.1991 .04 & $(0.531$ & $(2,135$ & 299 & 1.12 & $(0.05)$ & 2.480 & 257 & 103 \\
\hline $1904608,1900,11$ & $\begin{array}{l}-1156 \\
(156)\end{array}$ & $\begin{array}{l}0.244 \\
(7.39)\end{array}$ & 396 & 127 & $\frac{-2.249}{(2.64)}$ & $(758)$ & 164. & 8 \\
\hline
\end{tabular}

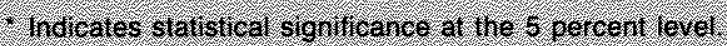

periods, the two measures could lead to different interpretations of monetary policy.

The adjusted monetary base has been used frequently in theoretical and empirical models of money stock control. Hence, one way to assess whether the difference in the two AMB measures is important is to see if either measure explains more of the movements in the money stock, M1. ${ }^{23}$

Some preliminary evidence on the relative performance of these alternative measures in controlling the money stock can be obtained by regressing changes in $\mathrm{M} 1$ on changes in the alternative base measures. Estimates of these equations using monthly data are reported in table $3 .{ }^{24}$ The results are reported for three subperiods from February 1959 to April 1991 based on important changes in the construction of the two series. The results indicate that, in all cases, there there is a statistically significant relationship be- tween changes in M1 and changes in each of the base measures. ${ }^{25}$ The relationship between M1 and either adjusted monetary base appears to have deteriorated since the effective implementation of the MCA in February 1984. This result ap. pears to be due, however, to the sharp rise in depository institutions' holdings of excess reserves following the December 1990 elimination of reserve requirements on non-transaction deposits and the sensitivity of ordinary-least-squares regression analysis to outliers. When the last five months of data are deleted, the adjusted R-squares are similar to those obtained over the first period-indeed, the adjusted R-square for the BOG's measure rises by nearly 20 percent. ${ }^{26}$

The relationship between M1 and the adjusted monetary base is somewhat tighter when the STL measure is used for all three periods; this is not the case when the last five months are deleted
${ }^{23} \mathrm{M} 2$ is not included in the analysis because. since December 1990, there is no direct relationship between the nonM1 components of M2 and policy actions. M2 can only be controlled directly through its $M 1$ component. Equations similar to those reported here, using $M 2$, produce results broadly similar to those here, except where noted below.

24 These equations are simple and are not intended to be the specification of the money supply process over the time period. Moreover, as Garfinkel and Thornton (1991) have shown, such a simple specification of the money supply function is inappropriate since February 1984. The strong serial correlation of the residual since then is evidence of this misspecification using either base measure. For these reasons, the results here are intended to be illustrative.

${ }^{25}$ The equations were also estimated using the growth rates of $\mathrm{M} 1$ and the two AMB measures. In all instances, the adjusted $R$-squares were smaller when growth rates were used. Qualitatively, the results are the same as those in the text when quarterly and annual data are used.

26As expected, after February 1984, there is no statistically significani relationship between $\mathrm{M} 2$ and either base measure, at the monthly of quarterly frequency. 
Table 4

\begin{tabular}{|c|c|c|c|c|c|c|c|c|}
\hline \multirow[b]{2}{*}{ Pertod } & \multicolumn{4}{|c|}{ St fous } & \multicolumn{4}{|c|}{ Board } \\
\hline & Constant & AAMA & A & b.W. & Gonstant & $4 \mathrm{AMB}$ & $f^{2}$ & 0.W \\
\hline \multicolumn{9}{|c|}{ OUARTERLY RESULTS } \\
\hline $1 / 59-10179$ & $(0.75)$ & $(2.254$ & 7.74 & 152 & $\begin{array}{l}-428^{\circ} \\
(2.06)^{\circ}\end{array}$ & $\begin{array}{l}2266^{\circ} \\
(1499)\end{array}$ & 732 & 1.41 \\
\hline $180+1,84$ & $\begin{array}{l}-1.250 \\
(0.50)\end{array}$ & $\begin{array}{l}3.066 \\
4.18)\end{array}$ & 507 & 2.32 & $\begin{array}{l}-1.858 \\
(0.58)\end{array}$ & $\begin{array}{l}3.678) \\
(3.45)\end{array}$ & 406 & 25 \\
\hline 104.119 .1 & $(10.23)$ & $\left(\begin{array}{l}2.148 \\
(3.02)\end{array}\right.$ & 231 & 37 & $\begin{array}{r}1.692 \\
(0.47)\end{array}$ & $(2.014)$ & 156 & \\
\hline 118411190 & $\begin{array}{l}8.096^{\circ} \\
(2.14)\end{array}$ & $\begin{array}{l}4.4066^{*} \\
(5.34)^{2}\end{array}$ & 524 & 42 & $\begin{array}{l}-7.089 \\
(1,55)\end{array}$ & $\begin{array}{l}4.360 \\
(4.15)\end{array}$ & 394 & \\
\hline & & & NOA & FESUI & & & & \\
\hline & $\begin{array}{l}2.321 \\
(0.71)\end{array}$ & $\begin{array}{l}2794 \\
(9,2)\end{array}$ & 75 & 82 & $(026)$ & $\begin{array}{r}2.85 \\
(8.75)\end{array}$ & & \\
\hline
\end{tabular}

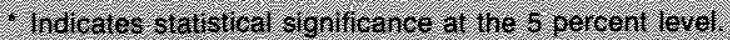

from the last period. ${ }^{27}$ Overall, the two measures appear to differ little in their relationship to monthly M1 growth.

Because the difference in the growth rates of the two AMB series declines at lower frequencies, the equations also were estimated using quarterly data and annual data for the period from 1959 to 1990 . These results are summarized in table 4 . The quarterly estimates are similar to the monthly ones; the overall perfor mance is better, however, using quarterly data during the first period and somewhat worse during the last. Again, much of the deterionation in the last period is due to including the quarters during and immediately after the elimination of reserve requirements on non-transaction deposits.

For quarterly data, the St. Louis measure al ${ }^{-}$ ways explains somewhat more of the variation in M1 growth. Estimates using annual data provide a similar result, with the STL series explaining about 4 percent more than the BOG series of the annual variation in M1.

\section{CONGLUDING REMARKS}

While no formal tests of the difference in the performance of the two base measures for money stock control have been made here, the differences might be statistically significant. Indeed, this has been the case in other applications. For example, Haslag and Hein (1990) have reported statistically significant differences in the explanatory power of the two monetary bases for nominal GNP. More importantly, Friedman (1988) and McCallum $(1988 a, b)$ report substantive differences in the performance of the two measures for monetary policy analysis.

The problem is that the two measures differ by their reserve adjustments, their treatment of vault cash and their methods of seasonal adjustment. While differences in the reserve adjustment procedures account for the bulk of the discrepancies, differences arising from the treatment of vault cash and seasonal adjustments have become more important in explaining short-run variations between the two series in the $1980 \mathrm{~s}$. Because there is little objective rea

${ }^{27} \mathrm{Also}$, the BOG's measure produces a higher adjusted

R-square than does the SIL measure in the last period

when monthly growth rates are used. 
son to prefer one method of technical adjustment over the other, there is little basis for choosing one measure over the other in empirical studies, when the two measures produce substantially different results.

In instances where the results are qualitatively the same but quantitatively different, such as the results reported here or by Haslag and Hein, the researcher must be content to choose the measure that performs "best" for the problem at hand. If the problem is money stock control, the preliminary evidence presented here suggests that the St. Louis measure holds an edge.

\section{RETERENCES}

Andersen, Leonall C. and Jerry L. Jordan. "The Monetary Base-Explanation and Analytical Use," this Review (August 1968), pp. 7-11.

Brunner, Karl. "A Schema for the Supply Theory of Money," International Economic Review (January 1961), pp. 79-109.

Burger, Alberi E. 'Alternative Measures of the Monetary Base," this Review (June 1979), pp. 3-8.

Burger, Albert E., and Robert H. Rasche. "Revision of the Monetary Base," this Review (July 1977), pp. 13-28.

Dickey, David A., Dennis W. Jansen and Daniel L. Thornton ${ }^{2 A}$ Primer on Cointegration with an Application to Money and Income." this Review (March/April 1991), pp. 5848.

Engle, Robert T., and C. W. J. Granger. "Co-Integration and Error Correction: Representation, Estimation and Testing," Econometrica (March 1987), pp. 251-76.

Farley, Dennis E., and Yueh-Yun C. O'Brien. "Seasonal Adjustment of the Money Stock in the United States," Journal of Official Statistics (1987), pp. 223 33.

Friedman, Benjamin M. "Conducting Monetary Policy by Controlling Currency Plus Noise: A Comment," CarnegieRochester Conference Series on Public Policy (Autumn 1988), pp. 205-12.
Garfinkel, Michelle R. and Daniel L. Thornton. "The Multiplier Approach to The Money Supply Process: A Precautionary Note," this Review (July/August 1991), pp. 47-64

"The Link Between M1 and the Monetary Base in the 1980s," this Review (September/October 1989), pp. 35-52.

Gilbert, R. Alton. "A Revision in the Monetary Base," this Review (August/September 1987), pp. 24-29.

"Now Seasonal Factors for the Adjusted Monetary Base," this Feview (December 1985), pp. 29-33.

"Calculating the Adjusted Monetary Base under Contemporaneous Reserve Requirements," this Review (February 1984), pp. 27-32.

"Two Measures of Reserves: Why Are They Different?" this Review (June/July 1983), pp. 16-25.

"Revision of the St. Louis Federal Reserve's Adjusted Monetary Base," this Review (December 1980), pp. 3 -10.

Haslag, Joseph $H_{2}$ and Scott E. Hein. "US. Monetary Policy Measures: Are They Roughly Equivalent?" mimeo, Federal Aeserve Bank of Dallas (1990).

Johansen, Soren. "Statistical Analysis of Cointegration Vectors," Journal of Economic Dynamics and Control (June/September 1988), pp. 231-54

McCallum, Bennett T. "Robustness Properties of a Rule for Monetary Policy," Carnegie-Rochester Conference Series on Public Policy (Autumn 1988a), pp. 173-204.

"Reply to Comments by Benjamin Friedman," Camegie-Rochester Conference Series on Public Policy (Autumn 1988b), pp. 213-14.

Meulendyke, Ann-Marie. "Possible Roles for the Monetary Base," in Intermediate Targets and Indicators for Monetary Policy: A Critical Survey (Federal Reserve Bank of New York, July 1990) pp. 20-66.

Pierce, David A., Michael R. Grupe, and William P. Cleveland. "Seasonal Adjustment of the Weekly Monetary Aggregates: A Model-Based Approach," Journal of Business and Economic Statistics (July 1984), pp. 260-70.

Tatom, John A. "Issues in Measuring an Adjusted Monetary Base," this Review (December 1980), pp. 11-29.

Zeller, Louis. "Weekly Seasonal Adjustment Program for the IBM S/360 Computer", unpublished manuscript, Board of Governors of the Federal Reserve System (February 15, 1972).

\section{Appendix \\ The Construction of the Two Adjusted Base Meas- ures Since February 1984}

This section discusses how each series, not seasonally adjusted, is constructed in two steps: the raw data series (called "source base" by STL and "not-break-adjusted monetary base" by the BOG) and the adjustment for reserve requirement changes. Table A1 shows the construction of the STL source base and the analogous BOG series and summarizes the differences between them. Similarly, table A2 shows the adjustments made to each series and their differences.

\section{The Raw Data}

The St. Louis Series. The STL source base measure is the sum of reserve balances at Federal Reserve Banks and currency in circulation-i.e., currency held by the public. As shown in panel $A$ of table $A 1$, reserve balances are de- 
Table A1

\title{
Calculating the St. Louis Source Base and the Board's Not-Seasonally-Adjusted, Not-Break-Adjusted Monetary Base (since February 1984)
}

\author{
4. $5 T$. \\ - RESERV BALANCES \\ - total reserte balances \\ - required alearng balances \\ 4 GURRENCY IN QRRGUNATON \\ - cutrency held by the nonbank bublic \\ 1. current rotar vaul 6 ash
}

$\$ 290759$

gor.

- TOTAL RESERVES

- volal reserve balances

62931

- recured dearng batanees

4. applied vaun bash

1. GUPRENOV FELDBS THE NONBANK PGBAC

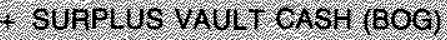

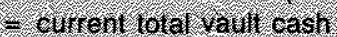

2. appled vilit cash at non bound banks

- applied valin cash at bound OEDS

- cument vaut cash al bound EDDS

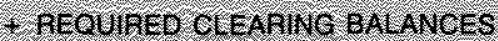

t LOAT PRICINA AS OFs

34090

35.714

256668

1.1 .624

223.000

33.669

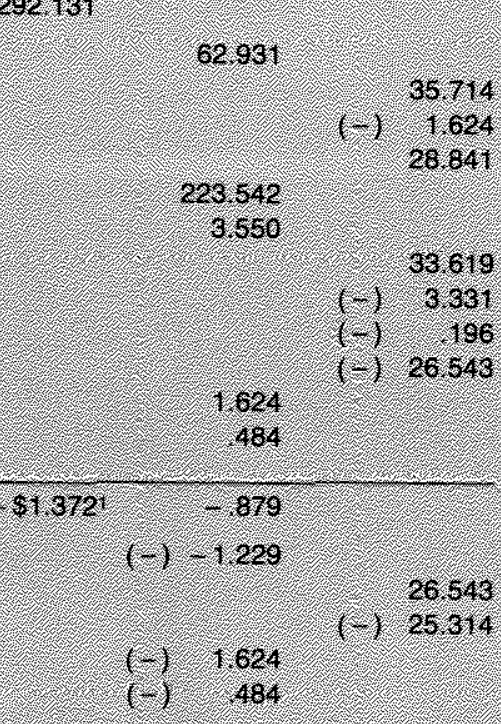

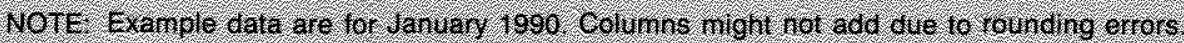

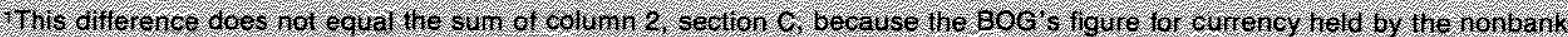

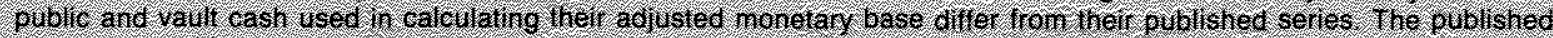

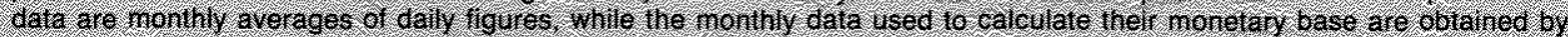
prorating date areraged over resene naintenarce perods

fined as total reserve balances net of required clearing balances of depository institutions. ${ }^{1}$

The Board of Governors' Series. As shown in panel B of table A1, the BOG's not-break. adjusted monetary base is essentially the same as the STL source base. Roughly speaking, the not-break-adjusted monetary base is the sum of total reserves and currency. Total reserves used in the calculation is defined as the sum of total reserve balances, net of required clearing balances, and applied vault cash. ${ }^{2}$ Required clearing balances plus currency held by the nonbank public and surplus vault cash are added to the measure of reserves. In constructing this monetary base series, the BOG defines "surplus vault cash" as current vault cash net of lagged (applied) vault cash held by both non-bound and bound depository institutions that report quarterly
Required clearing balances are deposit balances that depository institutions are required to maintain at the Federal Reserve to ensure that the dollar volume of their check clearings and other transfers of funds through the Federal Reserve System are covered. These balances are subtracted from total reserve balances since they do not satisfy statutory reserve requirements and, hence, do not constrain a depository institution's expansion of deposit fiabilities explicitly.

${ }^{2}$ As noted in the main text, applied vault cash refers to the vault cash held by depository institutions during the two. week period ending 30 days before the end of the current maintenance period. 


\section{Table A2}

\section{Calculating the St, Louis Adjusted Monetary Base and the Board's Break-Adjusted Monetary Base, Not Seasonally Adjusted (since February 1984)}

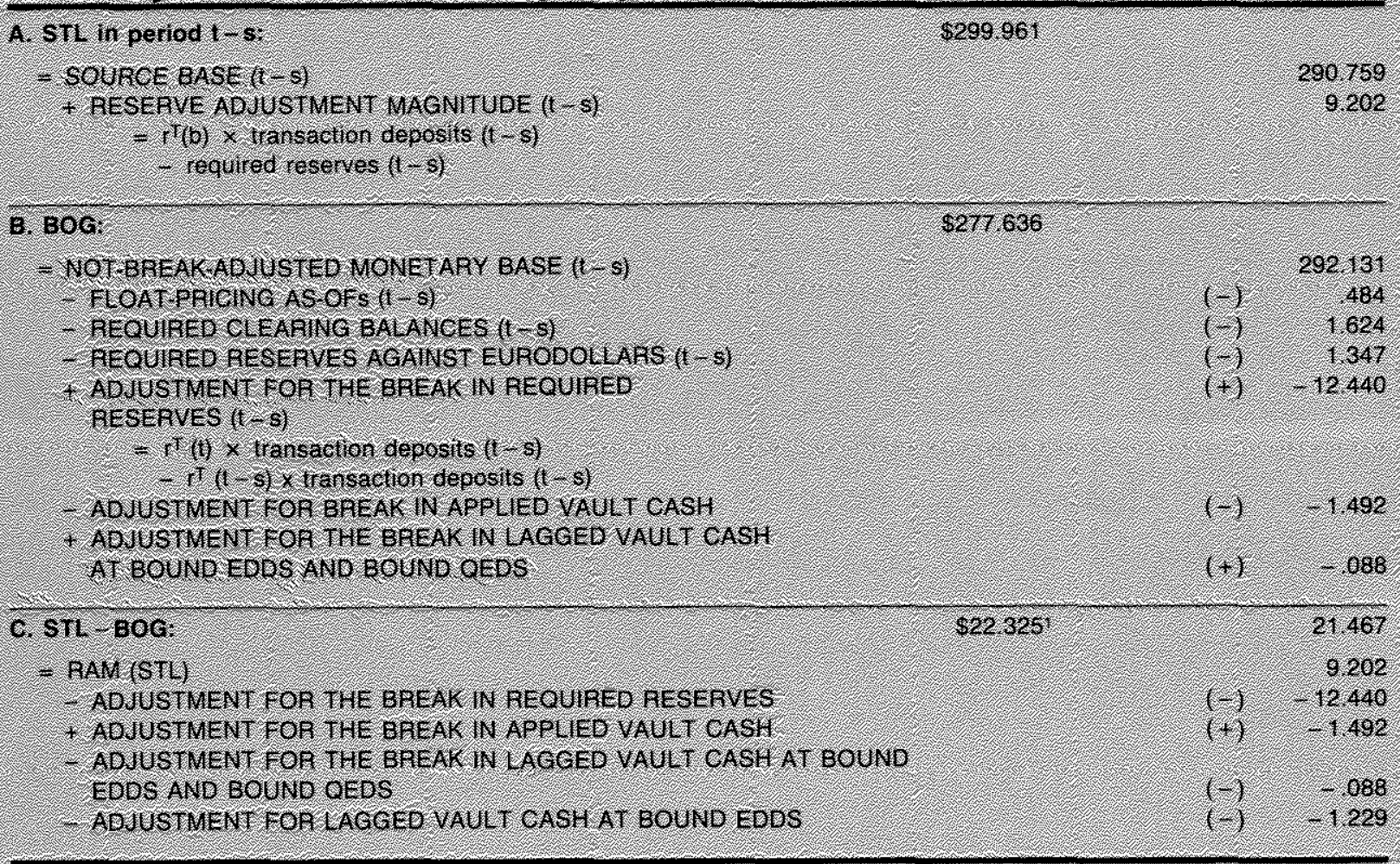

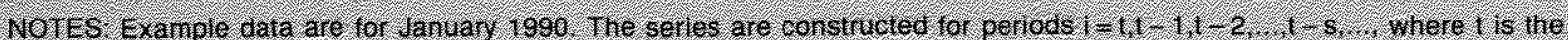

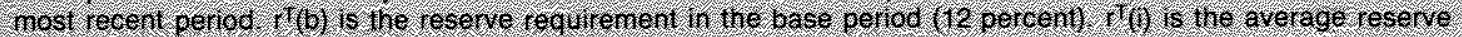

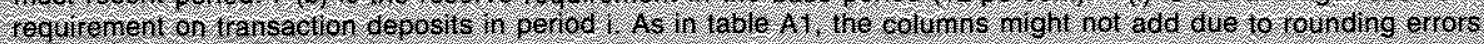

This does rol equar he sum of coltinn? secion $C$.

(QEDS) and net of current vault cash held by bound institutions that report weekly (EDDS). ${ }^{3}$

As shown in panel $\mathrm{C}$ of table $\mathrm{A} 1$, the key difference between the STL source base and the BOG's unadjusted base measure is the treatment of vault cash held by bound EDDS. In particular, the two measures are essentially identical except that the Board's measure excludes the surplus vault cash of bound EDDS-i.e., current vault cash net of lagged applied vault cash at bound EDDS. The two base series also differ in that the BOG's measure does not remove required clearing balances and includes floatpricing "as-ofs." As noted in the main text and below, however, required clearing balances and float-pricing as-ofs are removed when the Board calculates its break-adjusted series.

\section{Adjustments for Reserve Require- ment Changes}

The St. Louis Series. Panel A of table A2 shows the computation of the STL reserve adjustment magnitude, RAM, which is simply added to the source base. RAM is the difference between actual required reserves and the reserves that would have been required, given the actual level and composition of deposits held at depository institutions, under the reserve re-
The measure of Surplus vault cash reported on the Board's H. 3 release is not the measure used in this com" putation. Rather than using current vault cash of all depository institutions, the surplus vault cash in the H.3 release includes lagged vault cash of only those institu- tions subject to reserve requirements. In addition, rather than subtracting current vault cash of bound EDDS, the surplus vault cash reported in the H.3 release subtracts applied vaull cash of these institutions. 
quirements of a chosen base period. The reserve requirement ratio on transaction deposits currently used for the base period is 12 percent, the marginal reserve requirement in effect since the full implementation of the MCA. ${ }^{4}$

This adjusted base measure indicates what the monetary base would have been given the current level of currency held by the nonbank public and the current level and composition of deposits under the base period's system of reserve requirements. If the required reserve ratio were to be reduced in any period, the adjustment would increase. ${ }^{5}$ In this case, the source base would not change initially, but the adjusted monetary base measure would increase as RAM increased, reflecting a release of reserves into the system available to expand deposit liabilities. ${ }^{6}$

The Board of Governors' Series. The BOG adjusts the series for breaks in reserve requirements historically. In particular, it treats the most current period as its base period so that the break-adjusted series and the unadjusted series are identical. Reserves are adjusted with

4The actual average reserve ratio is lower than 12 percent because, for the individual bank, the reserve ratio is only 3 percent for transaction deposits below the reserve tranch and 12 percent for deposits in excess of that tranch. Even betore last year's elimination of reserve requirements on personal time and saving deposits, which was completed in two steps starting in the middle of December 1990 and ending after the first matntenance period in January 1991 , the STL_RAM assumed that base period requirements on non-transaction deposits were zero. It should also be noted that both RAMs assume that the base period require ments on Eurodollar deposits is zero since February 1984.

5For example, the recent elimination of reserve requirements on non-transaction deposits released about $\$ 13.6$ billion during the two (two-week) matntenance pert ods starting in the middle of December.

6Typically, however, the Fed offsets the release of reserves generated by a reduction in reserve requirements, at least partially, by removing reserves from the banking system. Sucth a defensive measure would prevent the money supply from accelerating in response to the reserve require. a ratio method. For any period in which the system of required reserves differs from that in the current period, required reserves held against these deposits are multiplied by the ratio of current required reserves to what reserves would have been required under the old system, given the current composition of deposits. As shown in panel $B$ of table $A 2$, this adjustment simplifies to a measure similar to the STL-RAM, where the base-period reserve requirements are replaced by the most recent reserve requirements. An adjustment for breaks in applied vault cash is subtracted and an adjustment for breaks in lagged vault cash at bound EDDS and OEDS is added. ${ }^{7}$ In addition, reserves held against Eurodollar deposits are excluded from this series after the switch to contemporaneous reserve accounting. ${ }^{8}$

As summarized in panel $\mathrm{C}$ of table $\mathrm{A} 2$, the main difference between these series (not seasonally adjusted) revolves primarily around the treatment of vault cash and the method of reserve adjustment. ${ }^{9}$

ment change. Nevertheless, the change in reserve requirements would affect the adjusted monetary base provided that the resulting release of reserves were not perfectly offset by such a defensive measure.

The adjustment for the lag in applied vaut cash at bound EDDS is not break-adjusted before the swith to contemporaneous reserve accounting. After the switch, the $\mathrm{BOG}$ also started to make the break-adjustment to lagged vautt cash at QEDS.

Because the STL-AAM assumes that the base period reserve requitements on Eurodollar deposits are zero, the Board's exclusion of reserves held against these deposits plays no role in explaining the difference between the two AMB series.

It should also be noted that the Board's series is adjusted for the annual increase in the reserve tranch as if the change were being phased in gradually over the whole year. An contrast, the St. Louis measure adjusts for the change when it occurs. See Meulendyke (1990), p. 59. 